REVISTA ANDALUZA DE ANTROPOLOGÍA.

NÚMERO 7: GITANOS/ROMA: AUTO-PRODUCCIÓN CULTURAL Y CONSTRUCCIÓN HISTÓRICO-POLÍTICA SEPTIEMBRE DE 2014

ISSN 2174-6796

[pp. 102-129]

http://dx.doi.org/10.12795/RAA.2014.i07.06

Fecha de Recepción: 07-06-2014

Fecha de Aceptación: 22-08-2014

\title{
PIEDRA, PAPEL Y TIJERA. VIVIENDA Y GESTIÓN DEL ASENTAMIENTO DE LA POBLACIÓN RROM / GITANA RUMANA EN EL ÁREA METROPOLITANA DE BARCELONA (2006-2014).
}

\author{
Óscar López Catalán \\ Universidad Autónoma de Barcelona
}

\section{Resumen}

La población rrom (gitana) rumana en el Área Metropolitana de Barcelona ha sido objeto cíclicamente de atención en relación con la vivienda por parte de los medios (particularmente en los momentos previos a unas elecciones). Dicha población, presente fundamentalmente en Badalona y Santa Coloma de Gramenet vive mayoritariamente en pisos; y es precisamente en este último ámbito en el que se concentran la mayor parte de las problemáticas que sirven como escenario para el conflicto (sobreocupación, acumulación de chatarra, etc.) sea éste más o menos magnificado por los actores políticos y los medios. Sin embargo, pocas veces las narrativas sobre el mismo van más allá de una esencialización cultural, analizando en profundidad los factores que intervienen en el acceso a la vivienda de dicha población. La intención de este texto, además de analizar someramente cómo se están construyendo dichos discursos, es ofrecer una visión concreta de la interrelación de diferentes factores y sus consecuencias sobre la propia población a partir de un trabajo etnográfico realizado en los últimos siete años.

Palabras clave

Gitanos, Rumanía, Vivienda, sobreocupación, gestión local 


\begin{abstract}
Romanian Roma population in the Metropolitan Area of Barcelona have cyclically been given visibility by media in aspects related with housing (particularly prior to elections). The majority of this population, residing mainly in Badalona and Santa Coloma de Gramenet municipalities, inhabits in flats; and it is precisely this subject the one that concentrates most of the issues pointed out as conflictive (overcrowding, scrap metal collection, and so on) being it magnified or not by the political actors and the media. However, almost never the narratives about that situation go beyond a cultural essentialism, analyzing in depth the factors that intervene in access to proper housing for that population. The aim of this text, aside of briefly analyze how these discourses are being constructed, is to offer a concrete perspective of the interrelation of different factors and their consequences on the population itself, using data from an ethnographic fieldwork conducted in the last seven years.
\end{abstract}

\title{
Keywords
}

Roma, Romania, Housing, Overcrowding, Local Management

\section{Introducción y aspectos metodológicos}

Desde el primer asentamiento de familias rrom rumanas, en los años 2002-2003 (ver, por ejemplo, Peeters, 2005; Vincle, 2006; Pajares, 2006; López y Sáez, 2009) en el Área Metropolitana de Barcelona ${ }^{1}$, uno de los aspectos que se han señalado con frecuencia como conflictivos es el de la vivienda (generalmente conectado bien a conflictos en el espacio público del barrio, bien a la cuestión de la sobreocupación). Aparte de la visibilidad que, en relación con otros temas (como por ejemplo los trabajos de tipo marginal, la política europea o las actividades ilegales) ha tenido la población gitana rumana en los medios de comunicación, este aspecto concreto ha sido recurrente en los debates y campañas políticas y en concreto en dos momentos determinados, la campaña municipal en 2007 y las elecciones al Parlament de Catalunya (2010). En consecuencia, el planteamiento de políticas a diferentes niveles sobre esta temática y/o población, en lugar de abordar otros factores desde un marco relativamente explícito, coordinado y coherente, se han llegado a constituir como reacciones bien a situaciones de urgencia, bien al propio conflicto y

1. Fundamentalmente en Sant Roc (Badalona), posteriormente en los barrios que componen Serra d'en Mena (Badalona y Santa Coloma de Gramenet) y en menor medida en diversos barrios de Barcelona. Más allá de su carácter institucional, que incluye un territorio mucho más amplio, menciono aquí el Área Metropolitana de Barcelona (AMB) para indicar que la investigación se ha realizado tanto en Barcelona como en algunos municipios adyacentes. 
al juego político asociado. Además, y como un factor fundamental en las dinámicas de exclusión, el rol de la vivienda e infravivienda ha sido y es fundamental en el arraigo en el territorio (en aspectos legales como el empadronamiento y la residencia) y en la movilidad (o el supuesto nomadismo; otro de los discursos habituales sobre la población rrom).

Sobra decir que la vivienda es un elemento central en las condiciones de vida de la población rrom rumana (como en las de cualquier otra) y, su acceso, uno de los problemas fundamentales a afrontar en el proceso de migración y asentamiento. Como veremos, es también un aspecto con implicaciones profundas en otros ámbitos, como por ejemplo el legal, además de condicionar directa o indirectamente tanto el acceso a ciertas posibilidades socioeconómicas o derechos básicos como la propia situación del mercado de vivienda (Onrubia, 2010). Es, además, un elemento en el que se combina un desconocimiento de las condiciones de vida de esta población y un claro imaginario negativo sobre ella, que se puede observar con claridad en los medios de comunicación y las declaraciones de los diferentes actores.

El texto usa como fuente, básicamente, información proveniente de un trabajo de campo etnográfico realizado durante todo ese periodo, vinculado a mi investigación doctoral y a otros proyectos ${ }^{2}$. Ésta proviene de la observación participante con la propia población y de la realización de entrevistas que entre sus elementos incluían la cuestión de la vivienda. Es importante destacar que el trabajo de campo se realizó de una forma fundamentalmente horizontal, con un importante componente de trabajo de calle y en otra diversidad de contextos, y sin mediación de otras instituciones o actores. En otras palabras, se trató de huir tanto de modelos de investigación basados en información de segunda mano (entrevistas a expertos, sumarización de informes) como de aquellos que, sin profundizar suficientemente en el contexto, tratan de obtener y generalizar datos rápidamente con un número reducido de entrevistas, generalmente a los perfiles más participativos o más accesibles (por ejemplo a través del movimiento asociativo).

La focalización en el trabajo de campo etnográfico abordó elementos muy diversos, pero entre ellos pronto adquirió fuerza la temática de vivienda: los primeros momentos de asentamiento; la presencia posterior de un "mercado segmentado", primero con pisos comprados a partir del acceso al crédito de población pakistaní (y otras) y después basado en la inestabilidad y el limbo inmobiliario creado por la crisis del ladrillo; parte de sus consecuencias (malas condiciones, precios altos, irregularidad, desalojos, situaciones de impago y embargos), así como las dinámicas de subrogación, movilidad y explotación.

2. De mi propio proyecto de investigación doctoral y de la etnografía con población rrom en el proyecto "Desigualdades Socioeconómicas y Diferencia cultural en el acceso a la salud en barrios de actuación prioritaria de Catalunya", convenio GRAFO (UAB) y Departament de Salut de la Generalitat de Catalunya, dirigido por Teresa San Román y realizado en colaboración con Meritxell Sàez. 
Todo ello se ha abordado desde una perspectiva teórica de la marginalidad y tomando como elemento central la situación de precariedad derivada de la situación en origen, el proceso migratorio, las limitaciones socioeconómicas y las estrategias utilizadas para superarlas.

De cara a contextualizar dicha información, o más bien los discursos sociales y el marco político asociado con la misma, resumiré primero algunos elementos de un análisis discursivo ya recogido en otro artículo (López y Aharchi, 2012). Los datos fueron recogidos mediante una búsqueda on-line en La Vanguardia, El País y El Periódico ${ }^{3}$ realizando una selección de las noticias vinculadas con la población y los discursos que sobre ella han mantenido tanto partidos políticos como otros actores. Aparte, utilicé también dos materiales difundidos por el Partido Popular en 2007 y 2010.

\section{Contexto y construcción mediática del conflicto}

A principios de febrero de 2007, una parte de los vecinos del barrio de La Salut (Badalona) realizaron manifestaciones contra las viviendas sobreocupadas (los llamados "pisos patera") en los que residían "gitanos rumanos". Mejor dicho, contra esa población, ya que la demanda fundamental era su expulsión. Los motivos más mencionados en prensa para estos hechos fueron la insalubridad, las molestias ocasionadas por la sobreocupación y, muy en relación con ellas, su comportamiento "incívico" y "delictivo", tanto en las propias viviendas como en el espacio público del barrio. En mayo de 2007, tres meses después de estas manifestaciones, el Partido Popular (que las apoyó) publicó on-line y en 30.000 DVD destinados a los vecinos un video titulado "7 minutos". En él se hablaba de "la falta de seguridad, que se atribuye al incremento de la inmigración ilegal; y el incremento de los pisos patera, que perjudican el bienestar de los vecinos" (El País, 8 de mayo de 2007). Calificado por SOS racismo y otros partidos de "racista" y "xenófobo", fue justificado por el candidato a la alcaldía por el PP Xavier García Albiol como una manera de "dar protagonismo a la gente de la calle" (El País, 5 de mayo de 2007:p1).

3. Tres de los diarios con un mayor número de lectores en Catalunya, según la Encuesta General de Medios. La búsqueda se realizó a partir de los términos "Gitano(s)", "Rumano(s)" y los nombres de las áreas en que se desarrolló el trabajo de campo.

4. Ver: http://www.youtube.com/watch?v=JkG3zWCDuko. El análisis del video daría para otro texto completo: el sonido de sirenas mientras aparecen inmigrantes con maletas (minuto 3:54), la música utilizada en el minuto 2:54 y sobre todo al final (5:10) y la manera en que están planteadas las preguntas, por citar tres elementos.

5. El Partido Popular (PP) es el principal partido de derechas a nivel estatal, gobernando en el momento de escribir este artículo tanto el estado como diversas autonomías y municipios (entre ellos Badalona, desde 2011). SOS Racismo es una ONG cuyo principal objetivo es luchar contra el racismo y la xenofobia y que se personó como acusación en el caso de los folletos mencionado aquí. El alcalde de Badalona fue finalmente absuelto del delito de provocación al odio y la discriminación en julio de 2014. 


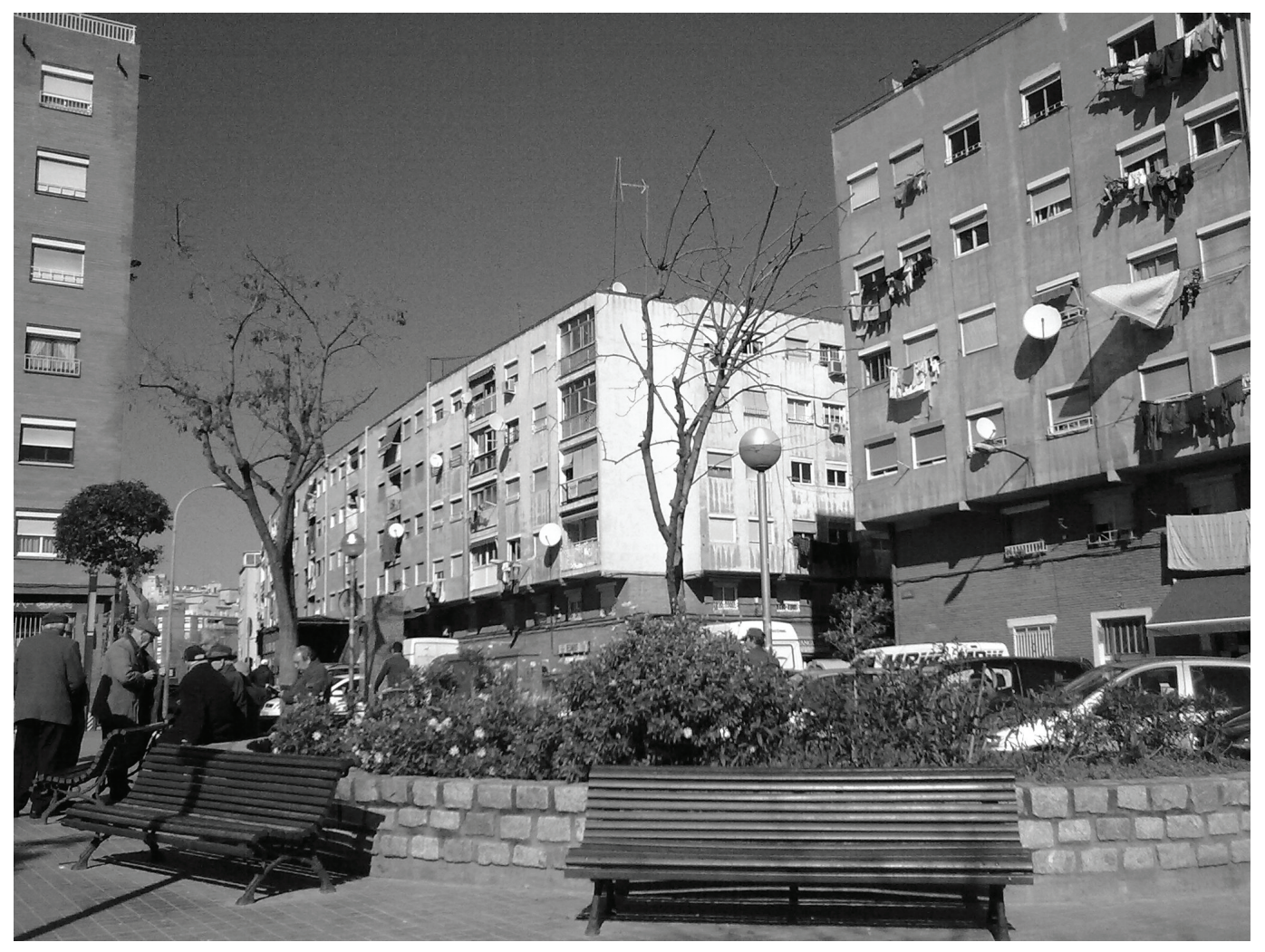

[Imagen 1 - Bloques del barrio de La Salut (Badalona). Febrero de 2009.]

En abril de 2010, la atención mediática volvió a centrarse en los mismos barrios: el PP de Badalona realizó un acto "informal" en un mercado público, repartiendo un folleto titulado “ ¿Tu barrio es seguro?”. En él, diferentes fotografías, teóricamente del barrio, mostraban acumulación de basuras, mobiliario urbano en mal estado y manifestaciones vecinales, junto con las palabras "suciedad" e "inseguridad". Se hacía, además, mención explícita a la población gitana rumana, con una foto de una pancarta con el lema "no queremos rumanos" y otra en la que se observaban dos mujeres con el atuendo "típico" de las gitanas rumanas, sentadas en un banco. El reparto del folleto fue justificado como una denuncia de la situación de los vecinos, que desean "salir por el barrio con la seguridad de no ser acosados o atracados" (El País, 24 de abril de 2010:p6) ya que "el colectivo gitano rumano que se ha instalado en Badalona ha venido a delinquir" (La Vanguardia, 25 de abril de 2010:p3). Ese mismo día, y los siguientes, otros partidos y actores expresaron su opinión, contraria (con matices, en algunos casos) a la postura expresada por el PP de Badalona. Entre ellas, las del entonces Alcalde de Badalona (PSC), de Felip Puig (CiU), de 
ICV y de una organización de inmigrantes rumanos ${ }^{6}$. Poco después, el Partido Popular de Catalunya y estatal matizó (sin desautorizar) el mensaje de dicho acto, mostrándose a favor de una migración "ordenada" y defendiendo su utilidad (La Vanguardia, 25 y 28 de abril de 2010).

Meses después, en septiembre de 2010, se da un nuevo episodio con la visita de una eurodiputada de la UMP, partido de Nicolas Sarkozy, a los barrios de Sant Roc y La Salut de Badalona junto con la presidenta del PP Catalán y el candidato a la alcaldía de dicha localidad. Dicha visita viene acompañada de nuevo de afirmaciones sobre la población gitana rumana, que establecía una similitud entre la situación de Francia -en esos momentos, en plena polémica por las expulsiones a Rumanía- y España, con los "mismos problemas de convivencia y seguridad" (El País, 17 de septiembre de 2010: p1), causados por la no integración, los conflictos y el "miedo" de los vecinos (La Vanguardia, 17 de septiembre de 2010: p3). Como en 2007, las noticias fueron acompañadas de declaraciones de algunos vecinos (incluidos gitanos españoles y otros ciudadanos rumanos no gitanos), dando cuenta de los problemas relacionados específicamente con esa población y mostrando su apoyo a las medidas propuestas (El País, 18 de septiembre de 2010: p5; La Vanguardia, 17 de septiembre de 2010:p13-15).

\section{Algunos elementos de construcción del imaginario negativo}

No descubrimos nada al señalar que lo anterior es un ejemplo de cómo la llegada y presencia de esta población, como de otras, se asocia con categorías negativas y amenazantes (delincuencia, problemas sociales o "de acogida", la llegada masiva o la "invasión"), omitiendo una determinada lectura del contexto social o la dimensión real del fenómeno (por ejemplo, que la llegada de población rrom es muy escasa en número). Como afirma Van Dijk (2005:53), "los inmigrantes se representan estereotípicamente como infractores de la ley y las normas, es decir, como diferentes, desviados y una amenaza para "nosotros". "Nosotros" como grupo o nación somos representados como víctimas, o tomando una iniciativa enérgica (policial) en contra de esta desviación." Se trata, por tanto, de colectivos y personas que vienen a lesionar a la población española (o incluso a otros inmigrantes "bienintencionados") en referencia a ese pretendido quebrantamiento de la "paz social" (Van Dijk, 2005:46).

En conexión con el nuevo racismo o racismo culturalista (Stolcke, 1995; Taguieff, 1987, 1991) estos discursos suelen implicar, entre otros elementos, el esencialismo cultural, la homogeneización y oposición "nosotros"/"ellos" y la negación del "racismo clásico".

\footnotetext{
6. Convergència i Unió (CiU), Partit dels Socialistes de Catalunya (PSC) y Iniciativa per Catalunya Verds (ICV) son partidos de ámbito catalán -los dos segundos con distintos niveles de federación con organizaciones políticas estatales- que pueden calificarse en ese orden como de un espectro conservador a uno de izquierdas. Felip Puig ( $\mathrm{CiU}$ ) era en ese momento Conseller d'Interior de la Generalitat de Catalunya.
} 
Como se puede observar en las declaraciones, los usos "desviados" del espacio público y de las viviendas son un elemento central, dándose, como afirma De la Haba (2004:125) una "representación predominantemente miserabilista y culturalista del "inmigrante", por la que suele establecerse una equiparación inmediata y acrítica entre inmigración, problemas sociales y desórdenes urbanísticos. Asociación ésta que se presenta anclada no sólo en el imaginario colectivo o en las representaciones mediáticas, sino también en numerosas teorías sociales que, abierta o soterradamente, tratan de explicarla apelando a la noción de "cultura'"' Ello implica no profundizar más en los condicionantes sociales (y las condiciones de vida), para asumir acríticamente (y de una forma no exenta de contradicciones) bien que el ocupante de la vivienda -y sus características innatas- es único responsable, bien que el problema reside en el racismo o el poco aprecio a la diversidad cultural de los vecinos. Finalmente, como apunta Martínez-Veiga (1999:7677), el "discurso higiénico" puede ser sólo una estrategia añadida -a la irregularidad en la tenencia y la precariedad en las condiciones de la vivienda- para justificar con una mayor facilidad un desalojo en caso que otro tipo de "presiones" no surtan efecto.

Aunque requeriría de un análisis más en profundidad es necesario decir que los procesos de homogeneización han estado presentes, de forma intencional o no, en los discursos de prácticamente todos los actores, desde el propio Partido Popular hasta otros partidos y ciertas asociaciones vecinales o incluso gitanas o de migrantes, además de ser también persistentes en el tratamiento de los medios: en primer lugar, por el uso generalizado de las categorías "rumano" o incluso "inmigrantes del Este". En segundo lugar, por ser una homogeneización de doble sentido, una oposición entre "ellos" y "nosotros", a partir de una idea básica: la de que al hablar de los "vecinos" se habla de la totalidad de los mismos, y, más aún, que la población rrom (u otras poblaciones inmigradas) no pueden ser calificados en ningún caso como tales. Sobre todo cuando, en un recurso también muy utilizado, se apela a "los vecinos de toda la vida" como un elemento de legitimación.

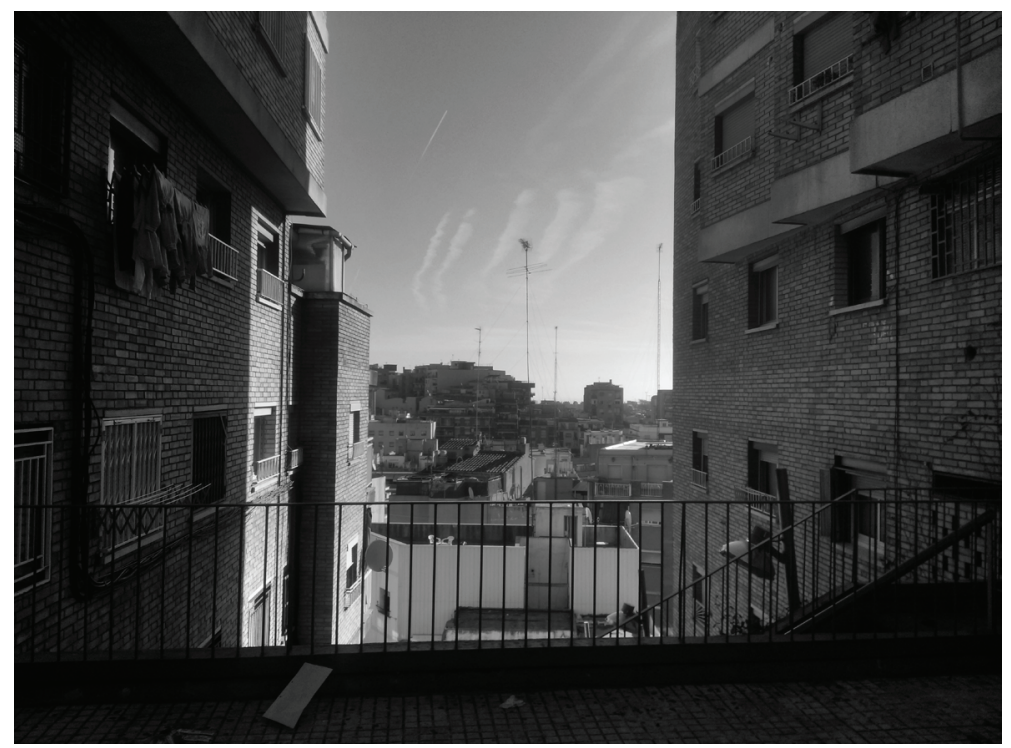

[Imagen 2 - Vista de Serra d'en Mena desde la C/Democràcia (Badalona). Febrero de 2014] 
La negación del racismo clásico es también extremadamente visible: no sólo es utilizada por los "vecinos", sino también en los discursos políticos, en los que la coletilla "no somos racistas" o "nos llaman racistas por decir lo que ocurre" aparece con mucha más frecuencia de la que reflejé en el análisis?. Ese uso del concepto de "raza" como opuesto a "cultura", juega aquí un claro papel de legitimación social del discurso, frente a posturas formalmente más radicales que siguen defendiendo una inferioridad genética o racial. Constituye por tanto un mecanismo de defensa frente a las posibles críticas al racismo, xenofobia o antigitanismo (Marushiakova y Popov, 2013) que pueden generar los discursos emitidos, y que efectivamente se pueden calificar como tales (entre otras razones porque están utilizando la cultura de una forma igual de inmutable que la propia concepción clásica de raza). En este sentido, el elemento fundamental es el uso esencialista de la cultura en la explicación de dinámicas afectadas por factores estructurales más globales, y que en muchos casos se convierte en un argumento para el rechazo y la justificación y aplicación de políticas concretas.

Ello se combina, además, con una dinámica de visibilización/invisibilización y desconocimiento compartida, en mayor o menor medida, con otros colectivos minoritarios y/o migrantes (Aramburu, 2005:35) particularmente si segmentos de los mismos se encuentran en posiciones marginales. Dicha invisibilización se expresa con claridad tanto por el hecho de que prácticamente nunca se da voz a una de las partes en la noticia (y cuando se hace, es desde unos parámetros muy determinados) como al observar las temáticas tratadas, que tienen menos que ver con las condiciones de vida en los barrios en los que residen que, por ejemplo, con el espacio público en el centro de Barcelona. La excepción es la visibilidad que se da a momentos concretos de conflicto en esas zonas, que en todo caso rara vez indagan realmente en las condiciones de acceso a una vivienda y la desigualdad socioeconómica en los barrios de la periferia. E incluso cuando se mencionan, generalmente se obvia que, como muestra Requena (2003) en un análisis de dichos barrios, se trata de procesos de "nueva marginalidad en espacios tradicionales de exclusión". Es decir, de una serie compleja de factores interrelacionados que producen que, muy habitualmente, los barrios tradicionalmente afectados por una peor situación sean los que recojan a población recién llegada. Como afirma Prieto (2007:167), que también analiza este caso, "[1]a prensa no se hizo eco -de forma positivani de las condiciones precarias o de pobreza en las que se encuentran las personas inmigrantes de origen rumano ni de la necesidad de llevar a cabo algún tipo de política social", y se limitó a reproducir y alentar los estereotipos enunciados por las personas que protestaban y a justificar, en muchos casos, las políticas de tipo coactivo por parte de las

7. “Aquí no tenemos campamentos de gitanos como en Francia, aquí la situación es aún peor”, aseguró. "Están repartidos por varios barrios de la ciudad haciendo la vida imposible a los vecinos y, encima, cuando nos quejamos, nos atacan y nos tachan de racistas" (El país, 20 de septiembre de 2010:p3-4). Es interesante ver también cómo este argumento se repite constantemente en los comentarios de las propias noticias. 
instituciones públicas sobre esta población y, en concreto, sobre aquella que habitaba en esas viviendas.

\section{La situación respecto a la vivienda de la población rrom rumana en Barcelona}

\section{El acceso a una vivienda: del mercado segmentado a la ocupación}

Durante el trabajo de campo efectivamente observé las malas condiciones en que en muchos de esos pisos vive habitualmente un segmento de la población rrom rumana en Barcelona. También algunos de los hechos narrados por parte de los vecinos (por ejemplo, en 2007), que indudablemente ocurren ${ }^{8}$; pero fundamentalmente las consecuencias vinculadas directa o indirectamente, como las relacionadas con la salud u otras relativas a la dificultad para el arraigo y el acceso a los servicios básicos. Todos esos elementos se han mantenido, de una forma u otra y hasta cierto punto, durante el periodo que abarca este texto. Sin embargo, como ya he mencionado, algunos parámetros en el acceso a la vivienda también han ido evolucionando junto con la movilidad de la propia población y otros factores estructurales -como los relacionados con el colapso de la burbuja y la crisis económica-, que han afectado al conjunto de la población (Rodríguez y López, 2011).

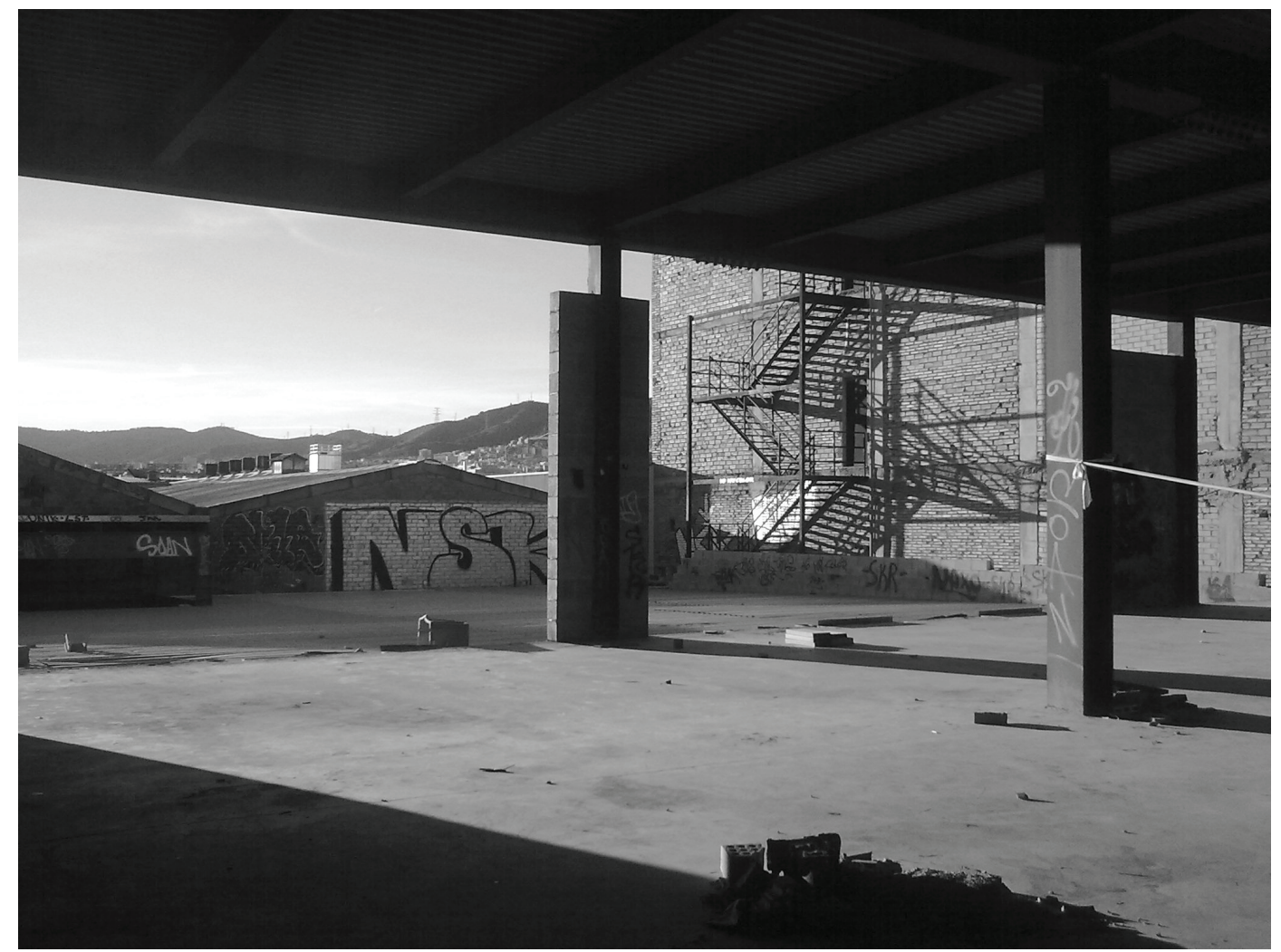

[Imagen 3- Fábrica abandonada y ocupada por varias familias en Barcelona. Febrero de 2009.]

8. Me refiero en particular al tema de la chatarra. Es destacable que en todos los medios se relataban, con matices, las mismas tres o cuatro declaraciones de vecinos (tanto para 2007 como para 2010), mientras su "representatividad" -asumiendo que es la opinión de todos los vecinos- no se pone en cuestión: si bien dichos discursos están muy extendidos, es importante señalarlo como un mecanismo más de legitimación. 
Como ocurre en muchas otras periferias urbanas europeas, existen y han existido segmentos de la población rrom rumana en situación de chabolismo o infravivienda en el $\mathrm{AMB}$, generalmente en asentamientos dispersos y poco estables. Chabolas improvisadas en solares, fábricas abandonadas, pequeños campamentos en los intersticios de las autopistas... Entre otras razones, la densa trama urbana y las actuaciones públicas no han permitido más que la subsistencia temporal de espacios reducidos y relativamente ocultos. Por tanto, a diferencia de lo que aún ocurre en otras ciudades, la mayoría de la población rrom rumana en Barcelona y los municipios adyacentes no se ha concentrado en espacios de ese tipo y se ha alojado y aloja en viviendas, aunque muchas veces éstas compartan algunos elementos similares de precariedad. En el periodo que va de 2003 a 2008, buena parte de dichos pisos se situaban en Sant Roc (Badalona): aunque el asentamiento de familias rrom allí se dio prácticamente desde el inicio de su presencia, fue muy especialmente a partir de los cambios en la política de visados de 2002 y algunos episodios en otros lugares: entre ellos está el desalojo de un recinto del barrio del Poblenou, las casernas de Sant Andreu y campamentos en otros municipios9. Posteriormente, y sobre todo desde 2007-2008, el peso de Sant Roc se fue haciendo menor en favor de otros barrios, fundamentalmente los que componen Serra d'en Mena (Badalona y Santa Coloma).

Respecto a la tenencia, hasta el estallido de la burbuja -alrededor de 2008- la mayor parte vivía arrendada, si bien en muy pocas ocasiones era únicamente el arrendatario y su familia la que residían en la vivienda ${ }^{10}$. Por ejemplo, de treinta entrevistas realizadas en 2008, el 70\% se encontraba en esta situación, más de la mitad de ellos sin contrato ${ }^{11}$, con todo lo que ello implica (ningún tipo de justificación ni recibo que permita demostrar que efectivamente se vive allí, desalojos por la fuerza en caso de impago o porque el propietario decide realquilar a otras personas ${ }^{12}$, abusos y presiones, etc.). En el periodo 2006-2008, el precio de los alquileres oscilaba generalmente entre los 600 y los 1000 euros, aunque en algún caso podía ser incluso algo mayor. Esto para pisos bajos o locales, interiores, mal distribuidos, con poca ventilación y en ocasiones sin alguno de los equipamientos básicos.

9. El campamento de la antigua fábrica Azulete, desalojado por el Ayuntamiento de Barcelona el 23 de febrero de 2004, llegó a acoger a unas 300 personas, aunque una parte de ellas eran población gitana portuguesa. La proporción de población rrom rumana en las casernas de Sant Andreu parece que era mucho menor (Pajares, 2006:246-247). Vincle (2006:42) también señala el barrio de Collblanc (L'Hospitalet de Llobregat) como uno de los lugares en los que en 2003 se produjeron desalojos.

10. Cabe aclarar que con arrendamiento me refiero al acceso y uso de la vivienda mediante el pago a un tercero que ostenta su propiedad, o que incluso controla el acceso a la misma sin tenerla, independientemente de si dicho acuerdo está formalizado con un contrato o no.

11. Las cifras eran en ese momento un poco diferentes para Barcelona (a favor del arrendamiento), porque algunas de las entrevistas se realizaron en otras localidades de Catalunya.

12. Incluso, en un caso, alquilar la vivienda a más de una familia, desapareciendo con el dinero de la fianza y el primer mes antes de que la segunda se diera cuenta de que la vivienda ya estaba ocupada. 
Aunque mucho más intensamente en la infravivienda, generalmente eran también de lugares peor ubicados, en zonas más alejadas y con menos posibilidades de accesibilidad física a medios de transporte y otros servicios ${ }^{13}$. Las fianzas o los gastos necesarios para el acceso inicial a la vivienda eran además muy altos, frecuentemente nada justificados, e incluían dos o más meses del precio mensual por anticipado.

Estas condiciones eran, en todo caso, relativamente comunes a las del mercado general de vivienda en la zona ${ }^{14}$, aunque dados los metros cuadrados, la situación geográfica y las condiciones, se trataba de precios claramente abusivos que se nutrían de las dificultades que la población rrom rumana tiene para poder alquilar una vivienda, más si cabe que para otras poblaciones inmigradas (Méndez, 2009:60; Carnero, Farré y Bosch, 2011). En concreto, las barreras han sido y son insalvables para el mercado "normalizado": exigencia de nóminas o ingresos estables en un contexto de trabajo marginal (mendicidad y recogida de chatarra o papel), problemas documentales, discriminación y racismo, y un largo etc.; pero también, y para una posible oferta informal, la falta de diversidad en sus redes sociales, entre otros.

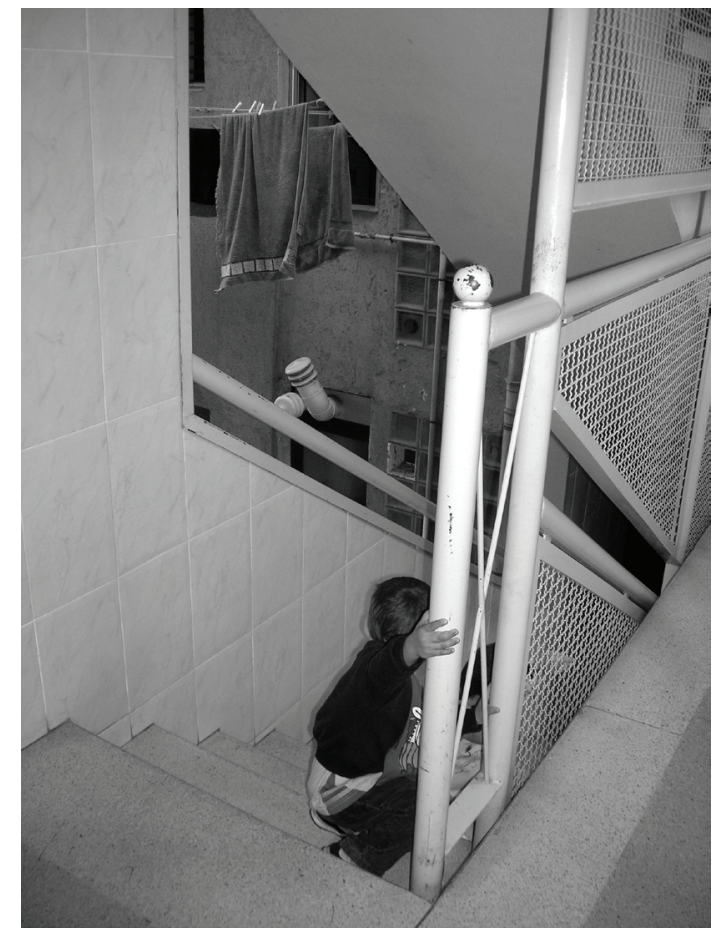

[Imagen 4 - Interior de uno de los bloques de Sant Roc (Badalona). Noviembre de 2006]

13. En todo caso dicha ubicación -exceptuando las situaciones de chabolismo- no es de una segregación ni lejanamente próxima a la que constaté durante el trabajo de campo en las localidades de origen, en las que una parte importante de la población rrom vive en barrios físicamente separados del centro.

14. Incluyendo las prácticas habituales por parte de algunas inmobiliarias: publicidad engañosa, fianzas muy altas y cobro de un mes por "gastos de gestión" sin recibo de ningún tipo, y por tanto, sin declarar. El objetivo era exclusivamente hacer negocio, independientemente de que pudieran darse problemas con la propia vivienda, de convivencia, o que los inquilinos tuvieran continuidad en el pago. 
Precisamente todas estas dificultades constituyeron durante años lo que podemos definir como un "mercado segmentado" de la vivienda (Martínez-Veiga, 1999:72): paralelo, informal y con poca interrelación con el resto de la oferta, no dependiente de inmobiliarias u otros actores. Segmentado también porque la gran mayoría de pisos en los cuales ha residido la población rrom rumana en Barcelona son o han sido propiedad de personas de origen paquistaní, o han sido alquiladas por estas (en los casos en que ha existido un subarrendamiento). Obviamente, dicho proceso tuvo que ver tanto con una mejor situación socioeconómica relativa de la población paquistaní como con las facilidades de acceso al crédito hipotecario propias del proceso especulativo. En todo caso, durante este periodo (y parte de los años siguientes) los gastos derivados de las hipotecas fueron cubiertos generalmente por los ingresos generados con el alquiler. Este hecho se refleja poco y mal en las noticias aparecidas en el periodo, y cuando lo hace (ver, por ejemplo, El Periódico, 7 de febrero de 2007:p2), llama la atención que se dé únicamente la versión del propietario y se hable de impago, mientras no se cuestiona el hecho de que en un local o piso, probablemente sin contrato, cédula de habitabilidad ni condiciones dignas, vivan 25 personas que pueden llegar a pagar un precio de 1000 euros al mes (El País, 5 de febrero de 2007:p7). Por otra parte, en otras noticias que no son objeto de análisis aquí, ha sido frecuente el recurso a las "diferencias culturales" en los conflictos en el barrio con población paquistaní, cuando lo anterior hace pensar que había claros factores económicos que podían estar interviniendo.

Esta situación sufrió cambios drásticos con la crisis económica que se inició en 20072008, con un fuerte impacto añadido en el estado español por el estallido de la burbuja inmobiliaria, los rescates bancarios y el aumento del desempleo. En los barrios en los que se realizó el estudio, como en muchos otros, dicho impacto a nivel de vivienda se hizo patente tanto para lo que tiene que ver con los propios propietarios (problemas muy intensos para hacer frente a las hipotecas), como para los arrendatarios sin contrato, que en ocasiones se enfrentaron a desalojos o presiones añadidas (de propietarios o instituciones bancarias) derivadas de la expropiación por impago. En este sentido, una parte significativa de los pisos en los que residían familias gitanas rumanas fueron pasando a manos de entidades bancarias, produciendo una situación difusa respecto a quién o cómo realizar el pago. Por ejemplo, en algunos casos, después de estar teóricamente pagando el alquiler (al propio propietario o a alguien "actuando en su nombre"), fueron llegando avisos de expropiación o desalojo a la vivienda o directamente el propietario desapareció, tras lo cual se dejó de pagar. Dada la situación previa de irregularidad y el volumen de pisos en esta situación muchas viviendas (para las que, de todas formas, pocas veces había un contrato válido) permanecieron, de facto, "ocupadas" a pesar del cambio de propiedad. 
Junto con lo anterior, sobre todo en los últimos años, se incrementaron nuevas dinámicas de tenencia "irregular" y un nuevo "negocio" en torno a las viviendas "recaptadas" por las entidades bancarias y cajas o incluso en manos de administraciones públicas. En pocas palabras, personas (no pertenecientes a la comunidad) localizan y abren viviendas vacías y/o embargadas para, después de cobrar una cantidad, vender dicho acceso, a veces realizando un contrato falso. En ocasiones se produce un solo pago (que suele ir de los 500 a los $1000 €$ ), por la llave del piso, mientras en otras los "intermediarios" cobran ciertas cantidades después. Finalmente, incluso en los escasísimos casos en los que existe algún ingreso estable y demostrable documentalmente -contrato laboral o $\mathrm{RMI}^{15}$ - los precios y las condiciones demandadas (racismo aparte) siguen siendo tan elevadas que en la práctica es casi imposible encontrar un piso de alquiler. Todo ello ha producido, además de que una mayoría de las familias vivan de ocupas, un nuevo "mercado segmentado": derivado del anterior, pero con características $-y$ consecuencias- diferentes.

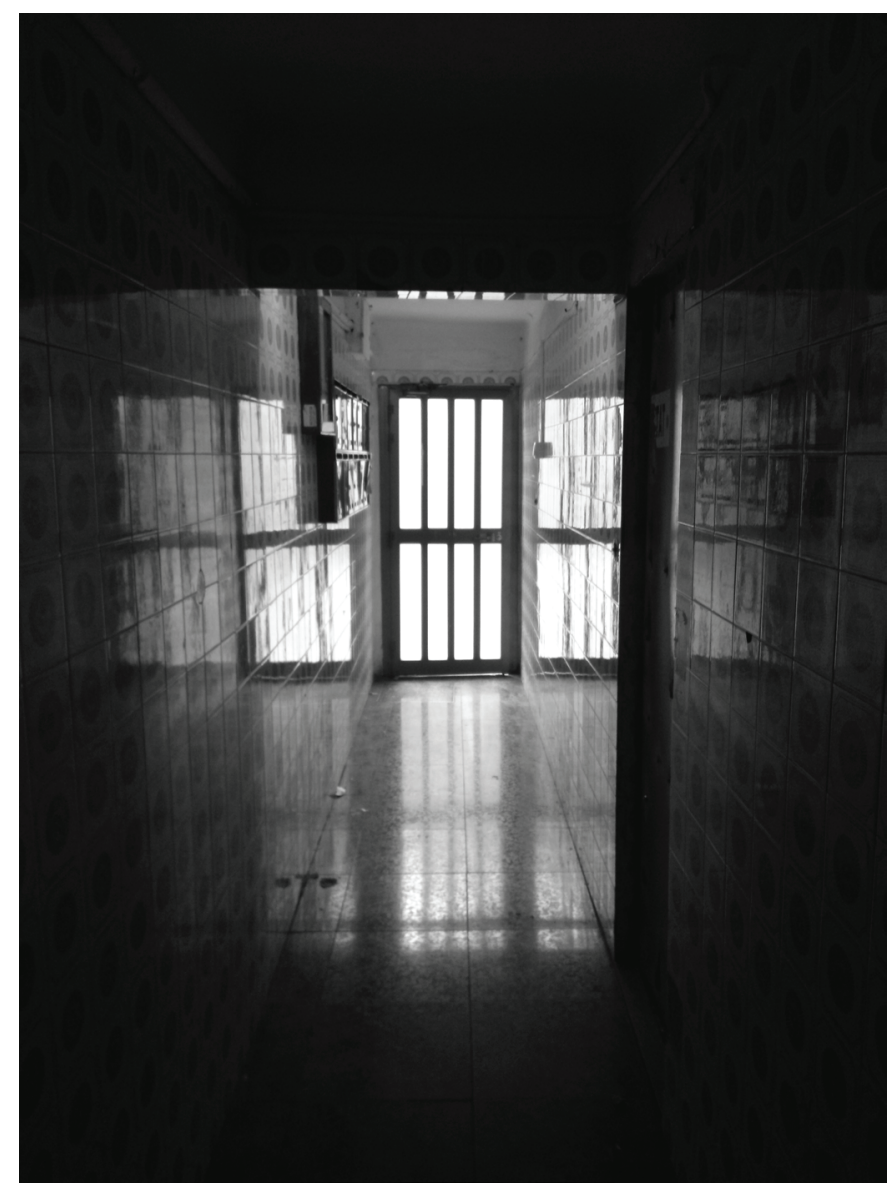

[Imagen 5 - Interior de un portal en Fondo (Santa Coloma de Gramenet). Mayo de 2013.]

\footnotetext{
15. La Renda Mìnima d’Inserció (RMI), o PIRMI, es una prestación de tipo económico que, de acuerdo con la Generalitat de Catalunya (www.gencat.cat) "tiene como finalidad el desarrollo coordinado de las acciones destinadas a ayudar a las personas que no disponen de los medios económicos suficientes para atender las necesidades esenciales de la vida en nuestra sociedad, mientras se preparan para la inserción o reinserción social y laboral.”
} 


\section{La sobreocupación y el subarriendo como estrategias de adaptación}

Obviamente las familias rrom no han sido actores pasivos en todo este proceso y han ido adoptando diversas estrategias para adaptarse a las limitadas posibilidades de acceso a una vivienda, entre ellas las que tienen que ver con la organización del uso y los gastos derivados de la misma. Los precios -dada la situación socioeconómica y laboral ${ }^{16}$ - han obligado prácticamente siempre a compartir una vivienda, a veces por periodos muy cortos de tiempo, y con criterios diferentes en función de su composición (una persona sola, una familia con hijos, etc.) u otros, como el momento de llegada. Sobre todo hasta 2008 y para un segmento de la población ${ }^{17}$, varias personas o unidades familiares por lo general emparentadas patrilinealmente y/o patrilateralmente, compartían los gastos del alquiler, siendo uno de los hombres el titular del contrato, o al menos el que informalmente poseía el derecho sobre la vivienda. Sin embargo, en los originarios de Murgeni y Calvini, con unas condiciones de precariedad e irregularidad mucho mayores, ha sido y es más habitual que las personas ocupantes de la vivienda no estuvieran emparentadas entre ellas.

Dichas cantidades no han ido sólo al pago de la vivienda en sí (mucho menos ahora, cuando muchos de los pisos están de facto ocupados) sino también a cubrir los gastos de luz, agua, etc. (cuando los hay) de forma compartida. La cadena de arrendamiento, por lo tanto, no se ha detenido generalmente en propietario y arrendador -si es que pueden definirse como tales-, muy particularmente en los pisos más precarios. En este contexto, aquellos con una mejor situación económica o legal y con posibilidad de conseguir con menor dificultad un contrato de alquiler o el pago de las cantidades necesarias han tendido a subarrendar habitaciones (o camas) a otros, muy particularmente cuando no son familia extensa. En algunos de estos casos, los menos, el pago era al propietario "real"18 del piso, cuando lo había. Pero en la práctica, para la mayoría, el resto de residentes realizan pagos individualmente - por ejemplo, de 50€/mes- a quien "tiene" el piso, es decir, a quien ha mediado para conseguir el acceso, sea éste cual sea. Esto ocurre también en ciertos casos en que la cantidad para acceder al piso fue obtenida como préstamo

16. Aunque son heterogéneas, me refiero especialmente aquí a las más habituales: algunos de los trabajos de tipo marginal (particularmente la recogida de chatarra a pie) que en ocasiones no permiten más que unos ingresos diarios de subsistencia -alrededor de unos $10 € /$ persona/día, en la actualidad- y dificultan enormemente una planificación a largo plazo.

17. Fundamentalmente el que tiene origen en Ţăndărei, debido a una mejor situación económica relativa. Ver López y Sáez (2009), para una explicación más detallada de los diferentes subgrupos de población rrom presentes en Barcelona, así como la evolución de su presencia. Actualmente es necesario también mencionar nuevos grupos, fundamentalmente procedentes de Calvini (Buzău) y Arad.

18. Las comillas son porque, como ya he mencionado, en algunos casos hubo terceros que se aprovecharon de las expropiaciones y cobraron sin tener, en principio, un vínculo formal con la vivienda. Pero también porque visto lo visto es fácil cuestionar que incluso quien tenía concedida una hipoteca fuera el propietario real -aunque sí formal- del inmueble. 
(de otros miembros de la comunidad), esperando recuperarla e incluso obtener cierto beneficio del subarriendo.

En un contexto como éste, de mercado paralelo, escasez, exclusión socioeconómica y precios elevados (ya fuera el alquiler o el acceso actual) es fácil entender que se den situaciones de sobreocupación. Pero, ¿qué alcance han tenido, más allá de su tratamiento por parte de la prensa? En primer lugar, la definición la sobreocupación en la bibliografía y en los criterios adoptados por las administraciones es, en general, bastante arbitraria. Partiendo del Decret 259/2003, sobre requisitos mínimos de habitabilidad, para una superficie útil mínima de 56 metros cuadrados se considera que pueden ocupar la vivienda en unas condiciones de uso adecuadas 6 personas (2003:2); un nivel de ocupación que para una proporción mayoritaria de los pisos en que residen familias rrom es significativamente mayor. En las entrevistas realizadas en 2008, y siguiendo ese criterio, casi un $40 \%$ se encontraba claramente en situación de sobreocupación (menos de $5.5 \mathrm{~m} 2 /$ persona) y más de la mitad de las personas en ratios que se podrían considerar límites con ella (hasta $8.8 \mathrm{~m} 2 /$ persona). Esta situación es coherente con los datos del trabajo de campo, aunque es desigual dependiendo del segmento de población del que estemos hablando: en el caso de la población originaria de Țăndărei, en ese momento, se podría estimar que el número de personas por vivienda oscilaba entre 6 y 15 personas -residiendo de forma estable y contando menores-. Este número es mucho mayor en el caso de la población con origen en Murgeni, que en la mayor parte de los casos llegaba incluso a cifras de 20 o 25 personas en algún caso. Ello hablando, en todos los casos, de pisos que raramente excedían o exceden -algunos han sido los mismos durante largos periodos de tiempo- los 60-65 metros cuadrados.

La evolución de las situaciones de sobreocupación ha dependido también, en ocasiones, del propio proceso migratorio y de movilidad de la población. Un buen ejemplo es lo ocurrido en los primeros meses de 2007, inmediatamente antes de iniciarse las manifestaciones mencionadas previamente. En ese momento una parte de las familias de Țăndărei (en una mejor situación socioeconómica) migraron hacia Reino Unido, con lo que parte de las viviendas que tenían alquiladas pasaron a estar vacías y ser ocupadas (con los mismos propietarios, y de nuevo con o sin contrato) por personas originarias de Murgeni. Dada la situación económica de estas últimas, entre otras razones, un mayor número de personas era necesario para pagar la renta mensual de dichos pisos, con lo que estos adquirieron un mayor grado de ocupación, lo que a su vez contribuyó al malestar vecinal.

Vemos, por tanto, como la sobreocupación ha sido un efecto tanto de la escasez de vivienda y la amplitud de las familias como una estrategia de adaptación y supervivencia en un contexto marginal. Paradójicamente, en los últimos años de recrudecimiento de la crisis es posible afirmar que quizás ha disminuido ligeramente y se ha tendido 
más, de nuevo, a adaptarse al modelo familiar. Sin embargo, al mismo tiempo, se ha incrementado la inestabilidad de las viviendas, a resultas de los desalojos por orden judicial (con procedimientos poco garantistas, en alguna ocasión; o como mínimo muy poco sensibles con las situaciones de exclusión y la capacidad para defenderse de personas que no tienen más que esa opción) y, en menor medida, de protocolos urbanísticos de los propios ayuntamientos (por ejemplo el cese de uso por las malas condiciones de la vivienda, en principio independientemente de cuál es su situación legal ${ }^{19}$ ).

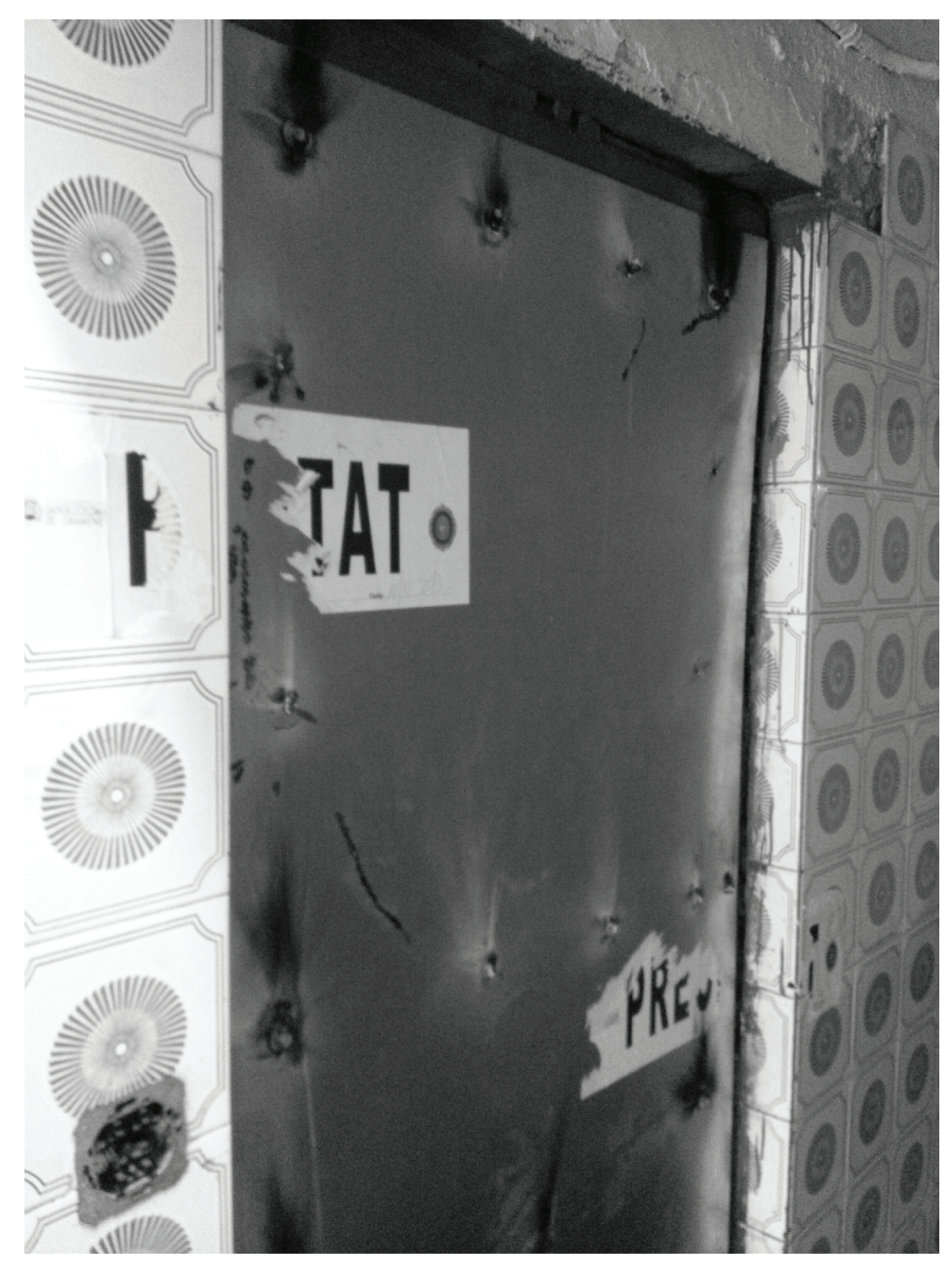

[Imagen 6 - Puerta precintada tras un desalojo en Santa Coloma de Gramenet. Mayo de 2013]

19. Digo independientemente porque es fácil deducir que las viviendas de familias en una peor situación socioeconómica, y por tanto generalmente también las más sobreocupadas y en una situación más irregular, son las que se encuentran en peor estado respecto a su habitabilidad y las que además suelen ser más visibles respecto a los protocolos urbanísticos. 
Cabe apuntar aquí, además, que los desalojos suelen producirse de una manera relativamente "silenciosa", generalmente sin una resistencia activa por parte de las familias y sin que haya observado, en ningún caso, redes explícitas de solidaridad vecinal como está ocurriendo en otros casos en esos mismos barrios. En todo caso estos desalojos suelen conducir al tapiado de los pisos y a la creación de una situación de sinhogarismo momentáneo y urgencia social -más aún cuando, entre otros elementos, estamos hablando en general de familias enteras, por lo que la proporción de menores es muy alta- a la cual frecuentemente las administraciones no quieren, o no pueden, dar respuesta. Por ejemplo, no en todos los casos los servicios sociales municipales tienen conocimiento de que se va a producir un desalojo, e incluso cuando lo hacen -a veces son las propias familias, si tienen referentes, las que informan de ello a partir de ser notificados-, no cuentan con recursos, protocolos o autorización para dar respuesta (aunque sea temporalmente) a la situación de vulnerabilidad creada por el desalojo. En estos casos, generalmente, la familia soluciona por su cuenta la situación (por ejemplo en casa de un familiar o transitoriamente en situación de calle hasta que encuentra otro piso) o bien se desplaza a otro territorio o país. Dicho desplazamiento, a veces a Rumanía, es en algún caso apoyado económicamente desde algunos municipios o servicios con el pago del billete al país de origen, con el compromiso de la familia de que es un retorno relativamente estable. Se da, por tanto, una situación que a diferencia de las expulsiones en el caso francés, no es fruto directo de una política explícita y dirigida, sino consecuencia de la desprotección y la incapacidad para hacer frente a situaciones de urgencia y vulnerabilidad social, y que a veces la propia familia demanda por la gravedad de su situación. Aunque estos procesos suelen darse con más frecuencia con quienes no han conseguido establecerse de una forma estable, supone también para éstos un impacto evidente en los procesos de arraigo, por ejemplo en el itinerario educativo de los hijos.

Para quienes no abandonan el territorio el nuevo acceso a una vivienda sigue haciéndose necesariamente en el mercado segmentado actual, al mantenerse las dificultades de acceso. En otras palabras: bien la ocupación o bien el acceso "mediado" (mediante pago, ya sea a quien la abandona o a quien la abre) a nuevas viviendas vacías u otras recién abandonadas, tras haber sido desalojados de una vivienda en las mismas condiciones. $\mathrm{Y}$ vuelta a empezar, en una dinámica que frecuentemente abarca más de un municipio y que en ocasiones implica la rotación entre los mismos pisos hasta que estos se "agotan" y se van sustituyendo paulatinamente. De hecho, en este contexto de irregularidad no hay garantía alguna de si un piso que se "compra" o al que se accede es ya objeto de actuaciones -si se ha dictado ya, por ejemplo, fecha de "lanzamiento"- o va a ser desalojado en breve. Es más, cuando ya es evidente que se va a producir un desalojo puede que el piso sea "vendido" a otros recién llegados o en una situación de urgencia, como intento de recuperar lo invertido, ignorando estos últimos que el "tiempo de vida" restante de esa vivienda ya está marcado. La necesidad de adaptarse a las barreras para acceder a un bien 
básico de subsistencia produce por tanto, también, dinámicas de explotación y estafa a diversos niveles, que en todo caso siempre pagan los más débiles de la cadena.

\section{Gestión del asentamiento, movilidad y fronteras}

No obstante, estas no son, ni mucho menos, las únicas consecuencias. Como ya dije, la población rrom en Barcelona no es una recién llegada, y existen muchas familias que han estado en la misma zona, con mayor o menor estabilidad, durante años. Sin embargo, un alto porcentaje de las mismas no ha estado ni está registrada a nivel local, en el padrón ${ }^{20}$. Como es bien sabido el proceso de empadronamiento implica formalmente un reconocimiento de la presencia y da acceso a algunos derechos y servicios básicos -salud y educación, entre otros-. Las familias rrom son conscientes de ello (y de las barreras que implican no tenerlo para la tramitación de otra documentación, prestaciones sociales, etc.). Y son también desde 2007 ciudadanos de la UE, con mucha menos presión explícita en cuanto a la irregularidad de su residencia y por tanto no aplica -al menos no de forma significativa- el rechazo a inscribirse por miedo a que dichos datos conduzcan a actuaciones que les perjudiquen o sean compartidos, por ejemplo, con la policía ${ }^{21}$.

Por lo tanto, si el padrón no se tramita no es ni porque no se resida de forma relativamente estable ni porque no se conozca o valore el procedimiento, sino porque no se articulan los medios para ello. Cabe recordar que las administraciones locales podrían (y deberían) registrar en el censo a cualquier persona una vez detectaran que reside de forma estable en el territorio, sea cual sea su situación de vivienda ${ }^{22}$. Sin embargo, como ya apuntara el Síndic de Greuges en un informe de 2008, el padrón se está utilizando en la práctica como una estrategia de control del asentamiento y de respuesta al fenómeno de los pisos sobreocupados (Síndic de Greuges, 2008:143). Con la excepción del Ayuntamiento de Barcelona (que al menos dispone de un mecanismo, aunque imperfecto, de empadronamiento sin domicilio fijo), esta situación ha permanecido relativamente invariable en el AMB desde 2007, generalmente porque ni existen procedimientos para empadronar en casos en los que no se cumple algunos de los requisitos. En consecuencia, tanto en los casos en los que no se reconoce la presencia en un piso porque no existe

20. Entre un 40-50\% sin empadronar, que en el proyecto mencionado en la segunda nota al pie, y como indican también otros estudios, es significativamente mayor que para otras poblaciones inmigradas.

21. De hecho en algún caso el intento de empadronarse, por los protocolos sobre el empadronamiento y la sobreocupación, sí que ha podido producir consecuencias negativas, por ejemplo la detección del inmueble por parte de guardia urbana.

22. Atendiendo a la Ley 7/1985, a una resolución del 4 de julio de 1997 y a la Ley 4/2000, cualquier persona viviendo en territorio español debe empadronarse y los ayuntamientos deben registrar a los extranjeros que "normalmente residen en el municipio". El decreto también especifica que en los casos de infravivienda (chabolas, campamentos, etc.) e incluso en caso de residir en un espacio público, dichos lugares deben aparecer como direcciones válidas en el padrón, mientras designan a los servicios sociales (u otras instancias) como los actores a quien corresponde identificar y certificarlas. 
contrato de arrendamiento -o se superan los límites establecidos de ocupación- como en aquellos en los que el asentamiento se produce en el espacio público, ésta práctica concreta ha implicado no hacer un esfuerzo por el arraigo (y la mejora de las condiciones de vida), sino el no reconocimiento de la presencia de ésta y otras poblaciones.

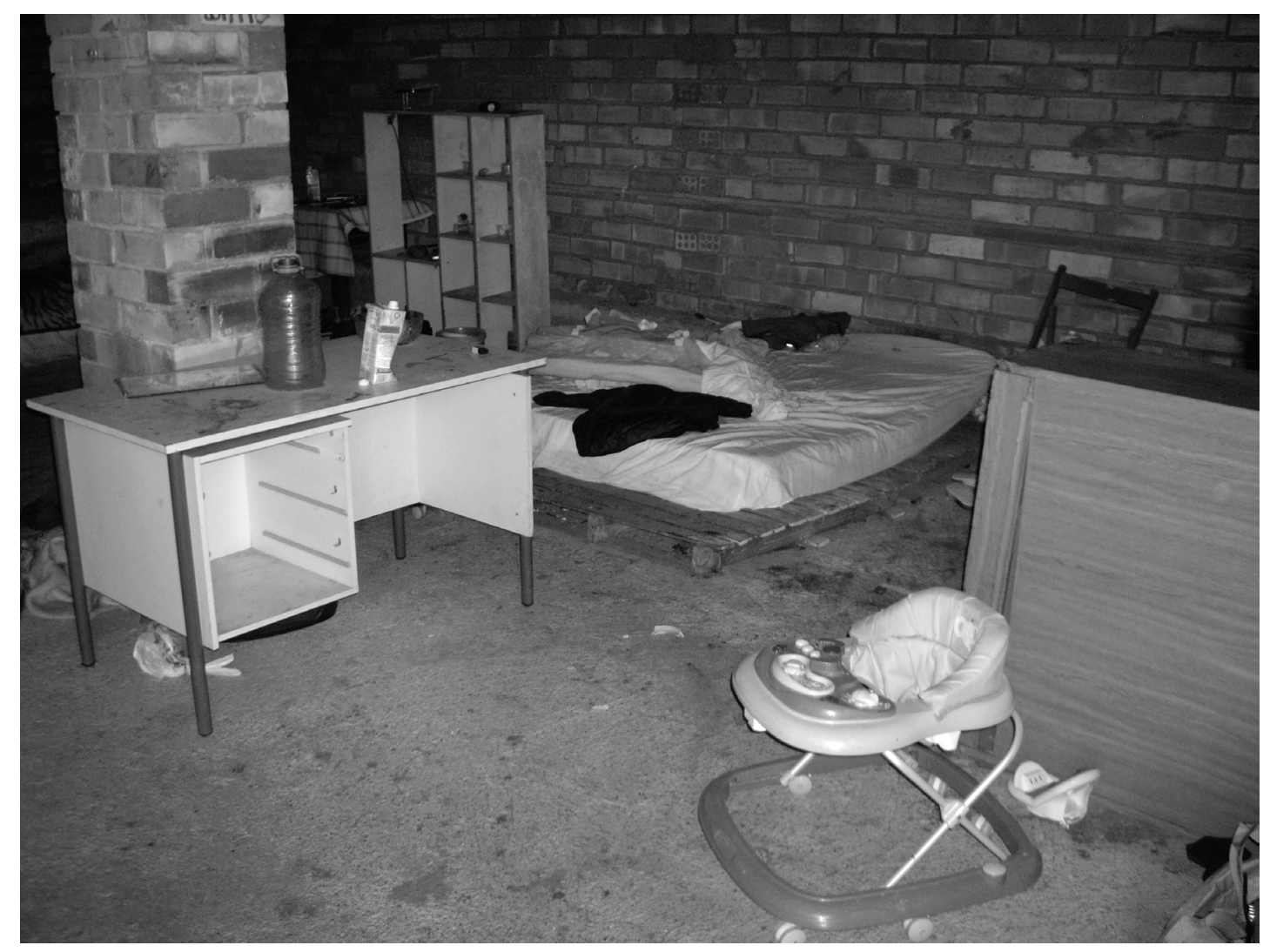

[Imagen 7 - Almacén abandonado ocupado por varias familias en Santa Coloma de Gramenet. Diciembre de 2007.]

Bloquear o no flexibilizar el acceso al empadronamiento no impide que sigan existiendo ni infravivienda, ni situaciones de sobreocupación ni problemas de convivencia. Es más, contribuye a las mismas, junto con la falta efectiva de intervención y determinadas construcciones discursivas. Y lo hace formalmente al menos de dos maneras, más allá de la retórica de negación de la ciudadanía que también supone: en primer lugar, incrementando las dificultades de acceso a derechos fundamentales (por ejemplo el acceso al sistema sanitario público o a la escolarización, pasando por la mayor parte de ayudas sociales). En segundo lugar, como un requisito más -durante años el fundamentalpara acceder a ciertos documentos, particularmente el Registro como Ciudadano de la Unión Europea residente, fundamental para multitud de trámites y para poder trabajar 
por cuenta ajena ${ }^{23}$. Dicho documento era relativamente sencillo de conseguir hasta mediados de 2012, siempre que se tuviera, además del padrón, un documento válido de identidad. Sin embargo, ha estado sujeto a ciertas condicionalidades ${ }^{24}$, que muestran también cómo la exclusión socioeconómica se construye a diversos niveles. Al haber impedido, por una parte, el trabajo por cuenta ajena durante amplios periodos de tiempo y, por otra, al exigir ahora demostrar ingresos o medios económicos para obtenerlo, se profundiza desde los niveles local y estatal en los factores que generan la exclusión y, con ella, se facilitan las retóricas de conflicto y expulsión.

Como plantean Legros y Vitale (2011) para Francia e Italia, se sitúa a muchos rrom en situaciones precarias e inciertas, mientras se favorece su desplazamiento, su visibilidad en círculos mediáticos y políticos y su constitución como un problema social. Y se parece optar aquí también, aunque con estrategias diferentes, por vías que sitúan a la población rrom, de alguna manera, como personas "que no deberían estar en el territorio", o al menos como un perfil particularmente no deseable y al que en cierto modo no debe facilitársele la estancia. En consecuencia, no parece haber inconveniente en que un desalojo o las propias condiciones de precariedad produzcan un cambio de piso o de asentamiento, siempre que el "problema" parezca desaparecer, aunque en la práctica abunde en la situación de precariedad y por tanto contribuya a reproducirlo. Con el agravante de que, además, dichas políticas son frecuentemente justificadas con la culturalización de una movilidad que, en realidad, es forzada ${ }^{25}$. Esta política, que podríamos calificar de "las desapariciones" o del "mirar hacia otro lado", contribuye como ya he dicho tanto a una movilidad territorial -por ejemplo, entre diferentes municipios- como a una circulación de familias de situaciones de calle a pisos y viceversa. Durante el trabajo de campo observé ejemplos muy concretos de ello, algunos de los más extremos en familias procedentes de Murgeni en una situación alternada de sinhogarismo, infravivienda y

23. Pajares (2006:259) apunta, por ejemplo: “Tampoco están siendo objeto de ningún programa específico de integración por parte del Ayuntamiento de Badalona. Los responsables del Ayuntamiento me expresaron sus reticencias a dedicar recursos para algún programa de este tipo, "porque no sabemos si desaparecerán del barrio de la noche a la mañana" (en referencia al nomadismo que se les supone a los gitanos)"

24. También conocido como "hoja verde" o NIE (a pesar de que la asignación de un Número de Identificación de Extranjeros es relativamente independiente), es en principio obligatorio para cualquier ciudadano de la Unión que quiera residir más de tres meses en otro país de la UE y acceder a ciertos derechos como tal.

25. En los periodos 2007-2009 y 2011-2013, se establecieron periodos transitorios en los cuáles dicho documento no permitía trabajar por cuenta ajena a ciudadanos rumanos. A partir de mediados de 2012, se traspuso también de forma más estricta la Directiva 2004/38/CE al ordenamiento español, hasta entonces relativamente laxo comparado con el de otros países europeos, añadiendo el requisito de mostrar medios económicos para no ser una carga para el sistema de bienestar del país receptor. En la práctica esto implica que registrarse como residente además del empadronamiento hay que demostrar también que se tienen varios miles de euros en el banco o que se tiene un ingreso regular. 
pisos sobreocupados (ver, por ejemplo, López 2012:106), aunque como ya he comentado existe también una gran movilidad entre los segmentos de población en una situación más precaria que viven habitualmente en pisos.

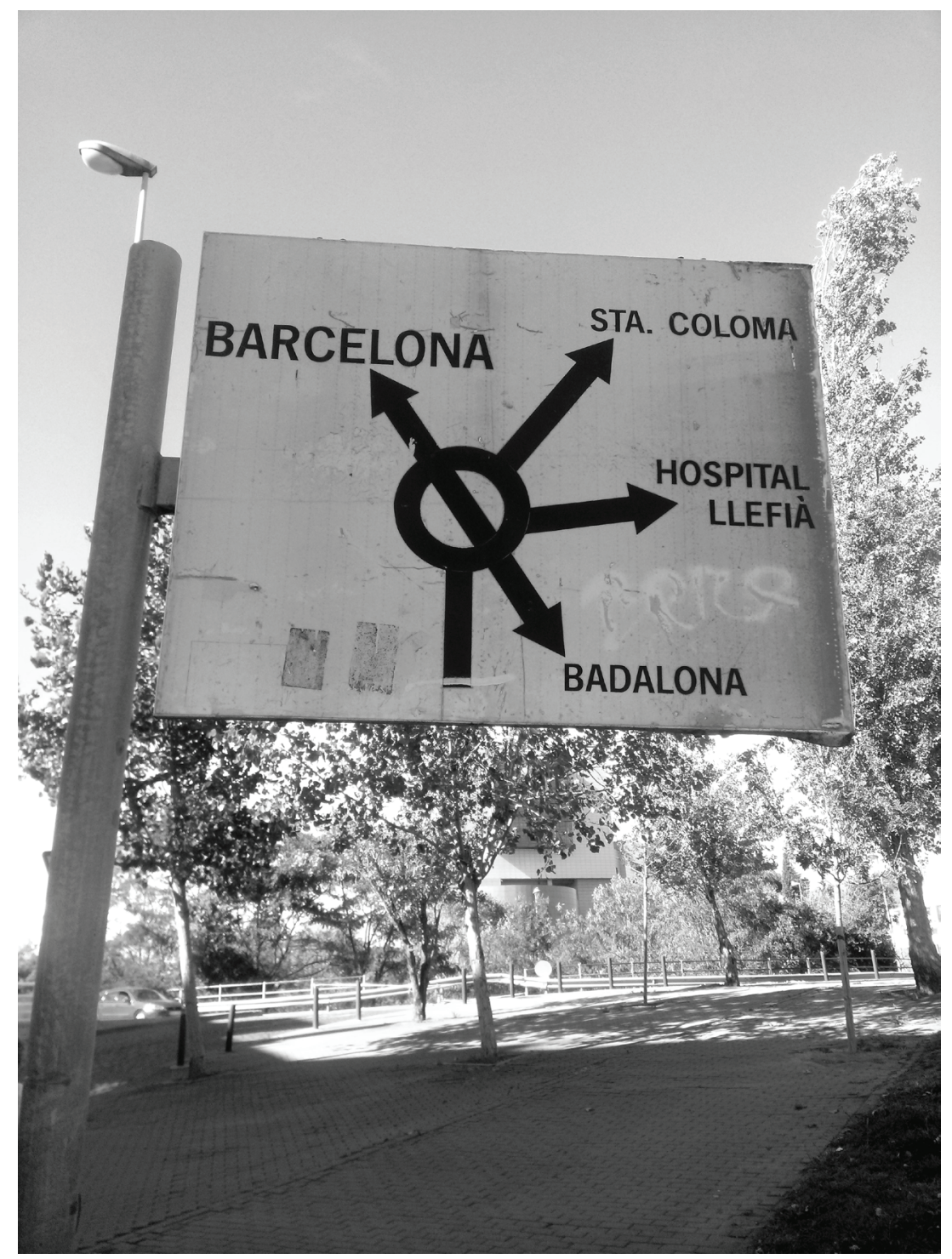

[Imagen 8 - Señal de tráfico en una rotonda que indica la división entre municipios. Septiembre de 2013]

Sin embargo, una mirada a largo plazo muestra que buena parte de la población sigue residiendo efectivamente en el territorio, resistiendo mediante estrategias marginales y un uso-aunque generalmente muy limitado- de los recursos públicos ${ }^{26}$. Como apuntan Chauvin y Garcés (2012), existe aquí una compleja y dinámica economía moral de inclusión y exclusión. Ésta se expresa, por ejemplo, en la contradicción entre la ciudadanía

26. Me refiero aquí tanto al acceso a ayudas directas o indirectas -sobre todo- como a los recursos destinados a proyectos de intervención, pasando por el uso de los servicios públicos (cuando puede accederse a ellos). 
teórica -como ya hemos visto estamos hablando de ciudadanos de la UE que ni tan sólo pueden registrarse como tales en el país/municipio en el que viven-, y la forma en que ésta es cuestionada por las desigualdades socioeconómicas y la aplicación práctica de un marco legal en un contexto de multigobernanza; local, regional, estatal y europea (Parker y López, 2014). De hecho, como señala Delanty (2006), las fronteras existen no solo en los bordes del territorio estatal, sino también en numerosos puntos en su interior y más allá de él. Son fronteras interiores (cuyas expresiones más evidentes son el control y la precariedad en las condiciones de vida) que se manifiestan una vez se ha vencido, al menos físicamente, "la frontera clásica, la frontera norte-sur, la frontera exterior" (Pretel, 2006:50). Y estas fronteras no son únicamente físicas, sino también económicas, étnicas, legales y sociales; de acceso a los recursos y servicios básicos; legitimadas y construidas por determinados discursos dominantes. Las desigualdades y tensiones sociales entre diferentes poblaciones y zonas urbanas acotan y marcan posibilidades de promoción, bienestar y acceso; y en este intento de disponer lo urbano, para una parte de los habitantes de la ciudad, ya no se trata tanto de "estar en los márgenes físicos de la ciudad, como en los márgenes virtuales de los principios organizativos, las reglas y los procedimientos previstos" (Cottino, 2005:105).

\section{Conclusiones}

Ni el arrendamiento sin garantías antes, ni la ocupación de pisos embargados ahora garantizan un acceso adecuado a la vivienda o una mejora de las condiciones de vida en los últimos años. Ahora bien, la presencia de población rrom inmigrada y la propia necesidad de un techo obviamente permanece: y, para bien o para mal, el volumen de pisos en manos de los bancos y los fondos de inversión es, en esta especie de limbo inmobiliario creado por la especulación y la burbuja en estos barrios, enorme. Igual de enorme que el rechazo que merecen algunas de sus prácticas: la negativa habitual a pactar ningún tipo de alquiler "social" o salida negociada; el tapiado de pisos sin aviso previo aprovechando que los ocupantes no están en él; la abrumadora superioridad de recursos en los procesos judiciales y, en definitiva, el aprovechamiento de un marco legal y político (con la connivencia o inoperancia de ciertas administraciones) poco o nada garantista en nada que no sea seguir observando la vivienda como un bien casi exclusivamente especulativo. 


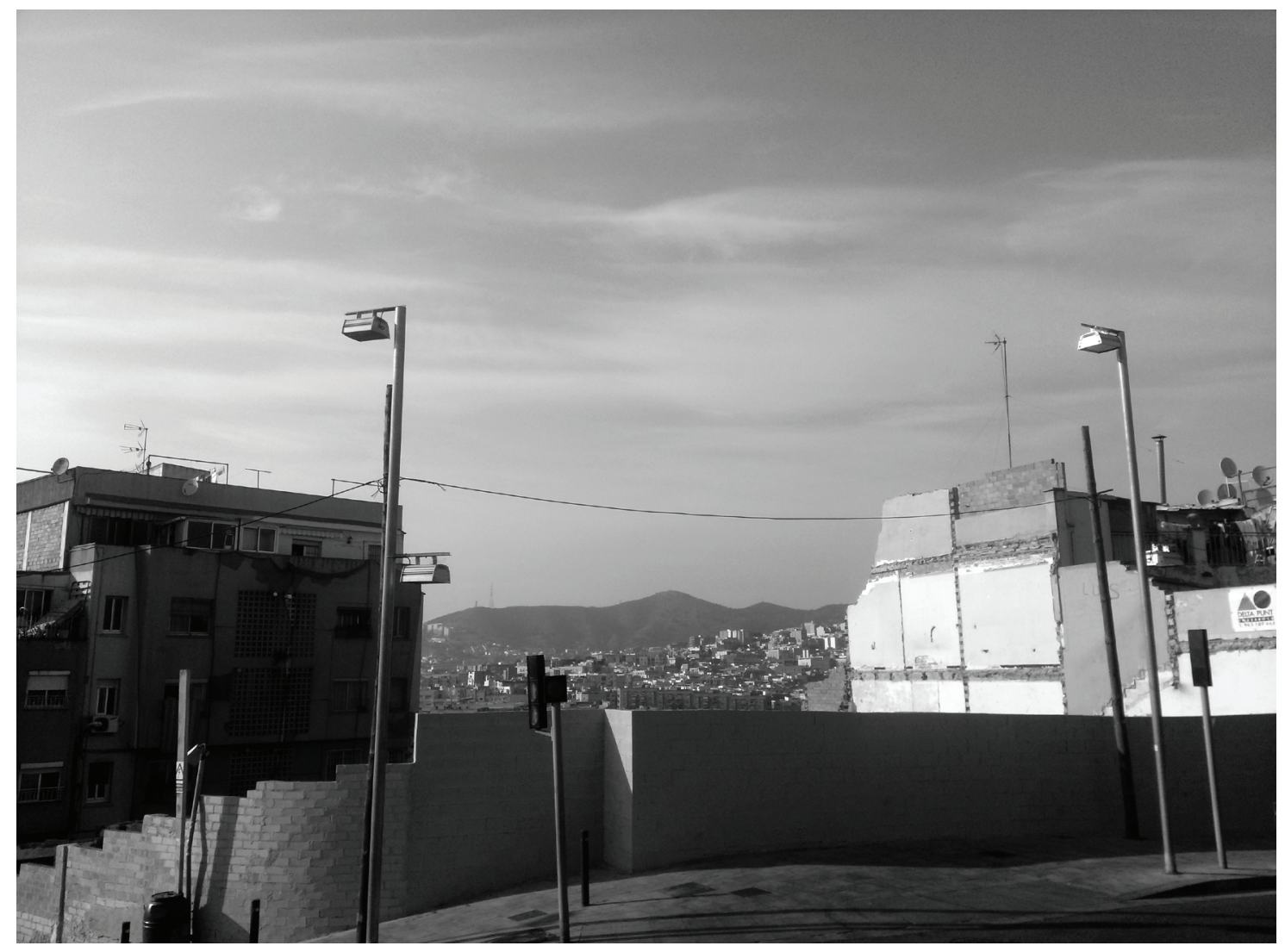

[Imagen 9 - Vista desde la C/ Circunvalación, frontera entre los municipios de Badalona y Santa Coloma de Gramenet. Febrero de 2014.]

El proceso especulativo en torno a la vivienda permitió, paradójicamente, la creación de un mercado segmentado de pisos que, junto con otros factores, evitó las grandes concentraciones chabolistas y de infravivienda de población rrom inmigrada en el AMB. Sin embargo, y vistas las consecuencias, esto no puede considerarse ni un éxito ni parte de un modelo de política de integración definido y efectivo: las prácticas irregulares -antes el mercado segmentado, ahora la "venta" del acceso a pisos vacíos- son consecuencia de una falta efectiva de políticas públicas sociales y en torno a la vivienda. Y es esa misma ausencia de políticas la que contribuye a que sean fáciles de articular ciertos discursos porque, al situar a la población gitana rumana en los márgenes del sistema socioeconómico no resulta de "utilidad" para él, ni por tanto para el sistema político que lo sustenta ( $\mathrm{y}$ en consecuencia puede y debe ser expulsada, directamente o mediante la inacción). A ello contribuyen, por lo tanto, no sólo los posibles réditos electorales sino también una concepción utilitarista en lo social y lo económico, desfavorable a las poblaciones que ocupan posiciones marginales. La siguiente cita de Teresa San Román es clarificadora: 
"[N]i tan siquiera puede decirse de ellos que estén en la clase baja [,] no si los concebimos como parte del engranaje social que produce y genera plusvalía sin que sus retribuciones les permitan mucho más que reproducir la misma situación que tienen. Puede decirse de ellos que están oprimidos porque se les niega el acceso a la propia organización social, viviendo en constante tensión por la supervivencia y por su propia autoestima. Pero no son explotados, porque no dejan, estos gitanos de los que ahora hablo, ni un duro que otro pueda capitalizar. El coste es la miseria de las chabolas. Pero no es una deuda pagada por la redención de las obligaciones sociales de un sistema de clases; es tan sólo el único rincón del mundo en el que les está permitido vivir. No hay en ello ninguna liberación romántica de la supeditación; más bien se trata del resultado de una adaptación forzosa y forzada a los desechos de una sociedad que sistemáticamente, sutilmente unas veces y con descaro increíble otras, les niega la entrada, y me temo que se la negará mientras haya payos suficientes para hacer lo que se necesite hacer." (San Román, 1991:187)

También para los rrom rumanos en Barcelona la miseria ha sido, en algunos casos, la de las chabolas, pero aún más frecuentemente la de los pisos sobreocupados, la insalubridad, el no tener tarjeta sanitaria, o residencia y permiso de trabajo. Y, volviendo al conflicto, es en gran medida el mantenimiento de esa situación de desigualdad en los barrios lo que lo alimenta (o lo que es utilizado para alimentarlo), más aún en un momento de crisis, y aunque esta estrategia se realice de formas diferentes: por ejemplo, en 2007, mediante un conflicto vecinal aprovechado por un partido para situarse en el centro del juego político en una determinada área urbana. En 2010, desde la utilización de las demandas vecinales previas, sin que existiera en ese momento ningún "detonante" previo, más allá de una misma situación sostenida en el tiempo y una convocatoria electoral.

Pero esta vinculación de los discursos con la gestión de la presencia en el territorio y la propia condición de ciudadanía (sean más o menos explícitas) no son patrimonio exclusivo de un partido político y no son sólo aplicables al ámbito concreto de las viviendas sobreocupadas o a la población rrom, sino también a aspectos más amplios como el acceso a derechos básicos y las dificultades para el arraigo. Prueba de ello es que la situación no difiere significativamente en la gestión de estos aspectos que se produce en diferentes territorios del AMB, que tienen o han tenido un color político diverso. Bien es cierto que en un contexto de gobernanza a diferentes niveles las posibilidades son limitadas, las responsabilidades se diluyen y son fáciles de obviar cuando hablamos de una población relativamente pequeña y desprovista de poder político, social y económico. También que los discursos y las formas pueden ser diversos e incluso aparentemente contrapuestos, mientras sus consecuencias concretas son equiparables. Pero no lo es menos que estamos hablando de cuestiones que están en la raíz del respeto a los derechos humanos fundamentales, y cuya conculcación y poca expresión en la práctica forman parte de una tendencia en aumento a nivel local, estatal y europeo: con regulaciones o prácticas 
diseñadas ad hoc; reaccionando a conflictos concretos, estereotipos y/o alarmas sociales creadas; en definitiva diseñadas más en torno al mercantilismo, la superficialidad y el juego político que adecuándose a la mejora de las condiciones de vida de la población.

No obstante, como dije antes, indudablemente el problema existe (respecto a la vivienda y respecto a cuestiones más generales), y afecta tanto a ciertos vecinos como a la propia población rrom. Sería absurdo negarlo manteniendo un discurso "buenista" o que caiga, desde una perspectiva opuesta -pero a veces con similares efectos-, en el resalte constante del valor de la "diferencia cultural" por encima de cualquier otra consideración, resolviendo la cuestión de un plumazo al describir a vecinos y partidos políticos como "racistas". Evidentemente, no se trata de no señalar con contundencia los elementos xenófobos y antigitanos -que son muchos- en dichos discursos y prácticas, sino de articular una explicación más amplia de los mismos y de los procesos sociales que los llevan aparejados. En otras palabras, de entender que la población rrom rumana y otras están siendo situadas frecuentemente y en determinados contextos en el papel de cabeza de turco respecto a situaciones de desigualdad y déficits del estado del bienestar producidos por el propio sistema. Y que de hecho estas dinámicas están estrechamente relacionadas con agendas políticas locales, aspectos de gestión y de financiación (siempre visibles, pero mucho más en los últimos años), y con la manera en la que los actores políticos tratan de lidiar con ellas, mostrando una imagen específica a la población en general y los medios de comunicación ${ }^{27}$ (27). Una imagen que es mucho más rentable si contribuye a esencializar al "otro" y a conflictivizar la relación con él para ocultar desigualdades sociales de tipo estructural y, en definitiva, para el mantenimiento del armazón simbólico y socioeconómico que las sustenta, que en buena parte se basa en no cuestionar precisamente a quienes no sufren $-\mathrm{y}$ se benefician- de dichas desigualdades.

27. Por ejemplo, observé durante el trabajo de campo cómo un recurso específico para la población rrom debía cambiar de denominación por la reacción que podría provocar por las dificultades de la población en general para acceder a ese mismo recurso. 


\section{REFERENCIA BIBLIOGRÁFICAS}

Aramburu, Mikel (2002) Los otros y nosotros. Imágenes del inmigrante en Ciutat Vella de Barcelona. Madrid: Ministerio de Educación, Cultura y Deporte.

Aramburu, Mikel (2005) "Inmigración y usos del espacio público." Barcelona.metropolis mediterránea (6) http://bcn.es/publicacions/b_mm/ebmm_civisme/034-042.pdf [Consultado el 10 de marzo de 2014]

Carnero, M.; Farré, L. y Bosch, M.A. (2011). Rental housing discrimination and the persistence of ethnic enclaves. IZA. Discussion Paper Series, (5583). http://econpapers. repec.org/RePEc:ivi:wpasad:2011-10 [Consultado el 18 de enero 2014]

Chauvin, Sebastien, y Garcés-Mascareñas, Blanca. (2012). "Beyond Informal Citizenship: The New Moral Economy of Migrant Illegality." International Political Sociology, 6(3), 241-259.

Cottino, Paolo (2005) La ciudad imprevista. Barcelona: Bellaterra 135 p.

Decret 259/2003, de 21 doctubre, sobre requisits mínims d'habitabilitat en els edificis d'habitatges i de la cèdula d'habitabilitat, Diari Oficial de la Generalitat de Catalunya, 3999 - 30.10.2003, 21327.

Directiva 2004/38/CE, del Parlamento Europeo y del Consejo, de 29 de abril de 2004, relativa al derecho de los ciudadanos de la Unión y de los miembros de sus familias a circular y residir libremente en el territorio de los Estados miembros (Diario Oficial de la Unión Europea -DOUE- L158, de 30 de abril de 2004).

Delanty, Gerard (2006) "Borders in a changing Europe: dynamics of openness and closure", Comparative European Politics, 4; 183-202

El País (2007) Agitación en Badalona por el incivismo. 5 de febrero de 2007.

El País (2007) El PP de Badalona distribuirá 30.000 DVD en los que se queja de los 'pisos patera'. 8 de mayo de 2007.

El País (2010) El PP reparte en Badalona folletos con el lema "no queremos rumanos". 24 de abril de 2010.

El País (2010) El PP se exhibe por Badalona con una eurodiputada de Sarkozy. 18 de septiembre de 2010.

El País (2010) El PP asegura que la inmigración es peor en Badalona que en Francia. 20 de septiembre de 2010.

El Periódico de Catalunya (2007) El incivismo motiva el éxodo de numerosos vecinos de La Salut. 7 de febrero de 2007.

La Vanguardia (2010) Un folleto del PP que vincula inseguridad e inmigración vuelve a levantar ampollas. 25 de abril de 2010.

La Vanguardia (2010) Rumanía se plantea querellarse contra el PP por el caso Badalona. 28 de abril de 2010.

La Vanguardia (2010) Una eurodiputada de Sarkozy ve "miedo" a los rumanos en Badalona. 17 de septiembre de 2010. 
Legros, Olivier y Vitale, Tommaso (2011). Les migrants roms dans les villes françaises et italiennes : mobilités, régulations et marginalités. Géocarrefour, 86(1), 2-14.

Ley 7/1985, de 2 de abril, Reguladora de las Bases del Régimen Local, BOE n 80 , de 3 de abril de 1985.

Ley Orgánica 4/2000, de 11 de enero, sobre derechos y libertades de los extranjeros en España y su integración social Boletín Oficial del Estado, núm. 10, de 12 de enero

López, Óscar (2012). "The genesis of a "Romanian Roma Issue" in the Metropolitan Area of Barcelona: urban public spaces, neighbourhood conflicts and local politics." URBS. Revista de Estudios Urbanos y Ciencias Sociales, 2(1), 95-117. http://nevada. ual.es:81/urbs/index.php/urbs/article/view/lopez_catalan [Consultado el 10 de abril de 2014]

López, Óscar y Aharchi, Noura (2012) "Discursos sobre la inmigración rrom (gitana) rumana en Barcelona. Estudio de la representación del "conflicto vecinal" y los trabajos marginales a partir de El País, La Vanguardia y El Periódico de Catalunya (20062011)." Discurso \& Sociedad, 2012, 6(3) 543-490.

López, Óscar y Sàez, Meritxell (2009) La població rrom immigrant de Romania a Catalunya: accés i ús dels serveis sanitaris catalans i situació de salut. Informe final del proyecto Desigualdades socioeconómicas y diferencia cultural en el ámbito de la salud en barrios de actuación prioritaria de Cataluña. Bellaterra: GRAFO-UAB.

Martínez-Veiga, Ubaldo (1999) Pobreza, Segregación y exclusión espacial. La vivienda de los inmigrantes extranjeros en España. Barcelona: Icaria-Institut Catalá d’Antropologia

Marushiakova, E., \& Popov, V. (2013). New Trends of Antiziganism in Central and Eastern Europe. In H. Kyuchukov \& O. Rawashdeh (Eds.), Roma identity and Anti-Gypsyism in Europe (pp. 183-194). München: LINCOM.

Méndez, Mónica (2009). Lopinió dels catalans sobre la immigració. Barcelona: Fundació Jaume Bofill - Editorial Mediterrània.

Onrubia, Jorge (2010). Vivienda e inmigración en España: situación y políticas públicas. Presupuesto Y Gasto Público, 61, 273-310.

Parker, Owen y López, Óscar (2014) Free movement for whom, where, when? Roma EU citizens in France and Spain. International Political Sociology [Aceptado para publicación]

Prieto, Óscar (2007). Sobre la identidad gitana y su construcción panétnica: El caso gitano en Barcelona. Tesis doctoral. Barcelona: Universitat de Barcelona. http://www.tesisenxarxa.net/TDX-0724107-083533/index.html [Consultado el 10 de marzo de 2014]

Partido Popular Badalona (2007) 7 minutos. http://www.youtube.com/watch?v=JkG3zWCDuko [Consultado el 10 de marzo de 2014]

Pretel, Óscar (2006) Las fronteras intermetropolitanas: el caso de Terrassa y la intervención del colectivo intercultural. En: Contrapoder. Fronteras interiores/exteriores. http:// transfronterizo.at.rezo.net/spip.php?article7 [Consultado el 10 noviembre de 2011] 
Resolución de 4 de julio de 1997, conjunta de la Presidenta del Instituto Nacional de Estadística y del Director General de Cooperación Territorial, por la que se dictan instrucciones técnicas a los Ayuntamientos sobre actualización del Padrón municipal. BOE núm 117/97, de 25 de Julio

Requena, Jesús (2003) La peor casa en el peor barrio. Barrios de inmigración y marginalidad en la periferia urbana de Barcelona. El caso de Badalona. [En línea] Scripta Nova. Revista electrónica de geografía y ciencias sociales. Barcelona: Universidad de Barcelona, vol. VII, no 146(058) http://www.ub.es/geocrit/sn/sn-146(058).htm [Consultado 10 de marzo de 2014]

Rodríguez, Emmanuel y López, Isidro (2011). Del auge al colapso. El modelo financiero-inmobiliario de la economía española (1995-2010). Revista de Economía Crítica, 12, $39-63$.

San Román, Teresa (1991) La marginación como dominio conceptual. Comentarios sobre un proyecto en curso. En Prat, J., Martínez, U., Contreras, J., Moreno, I., eds. (1991) Antropología de los pueblos de España, Madrid: Taurus Universitaria. 151-158

Síndic de Greuges (2008) La gestió municipal de l’empadronament dels immigrants. Barcelona: Sìndic de Greuges

Stolcke, Verena (1995) Talking Culture: new boundaries, new retorics of exclusion in Europe. Current Anthropology, 36, 1995; pp. 1-24.

Taguieff, Pierre-Andrè (1987). La Force du Préjugé. Essai sur le Racisme et ses Doubles. París: Editions La Découverte.

Taguieff, Pierre-Andrè (1991). Face ou racisme. Vol.1. Les moyens d’agir. París: Editions La Découverte/Essais.

Van Dijk, Teun (2005). Nuevo racismo y noticias. Un enfoque discursivo. En: Nash, M., Tello, R., Benach, N. [eds] (2005). Inmigración, Género y espacios urbanos. Los retos de la diversidad. Barcelona: Bellaterra. 